\title{
Management of Waste Material for Construction Industry
}

\author{
${ }^{1}$ Darshan Patel, ${ }^{2}$ Mayuri Prajapati, ${ }^{3}$ Neetu Yadav \\ ${ }^{1}$ ME Student, ${ }^{2,3}$ Assistant professor, Department of Civil Engineering, S.N.P.I.T \& R.C, Umrakh, \\ Gujarat, India. \\ 1'dasupatel1294@gmail.com, ${ }^{2}$ mayuri.prajapati64@gmail.com, ${ }^{3}$ neetuyadav@yahoo.com
}

\begin{abstract}
Construction waste generation and handling issues have been in focus to achieve sustainable goals. Considering the growth of construction in India, it is appropriate to link generation of construction waste with the growth. It measures to minimize and handle the construction waste are not developed and efficiently adopted, then it may threat for environment. In this research study, Residential construction case studies have been referred to identify the quantum of waste and source of wastage on the projects. Based on the identification of major waste generation on site, how the mitigative steps has been taken that also included in the form of frame work for minimization of waste on the site.
\end{abstract}

Keywords : Construction waste, reduce, recycling, re-use.

\section{INTRODUCTION}

The waste generated mainly consists of inert and nonbiodegradable materials such as concrete, plaster, wood, metal, broken tiles, bricks, masonry etc. These wastes are heavy, having high density, very often occupy considerable storage space either on Road sides or communal waste bins. India is a developing country where the growth rate is increasing and side by side waste material is also increased So there is a need of the management of waste material in India. Due to the increase in population, IT sector, new infrastructure projects and industrialization, the construction industry has shown very fast growth. Builders face the problem of financial difficulty due to the excessively material wastage in construction projects. The harmful effect of the waste material is on our general environment, philosophy of art, beauty and on our health. There are excessively wastage of material, inappropriate management of material and low awareness about reduction and proper utilization of waste material is very common in the local constructions sites in India.

\section{OBJECTIVES}

$>$ To determine the quantity and sources of construction waste.

$>$ To suggest imitative measure for reducing/reusing/recycling of waste in the construction industry for sustainable development.

\section{RESEARCH METHODOLOGY}

To conduct the research study six ongoing construction site has been selected. Among which three from private sector and three from government sectors. Then Data has been collected from each construction site related to material which having bulk in quantity of waste.

\section{LITERATURE REVIEW}

Florin-Constantin Mihai et. al. 2019 Said to the great recovery and recycling potential is lost via the lack of waste collection facilities (wild dumps) or poor recycling schemes (landfill based systems). Illegal dumping and landfills are the main disposal options across the world, causing environmental pollution, deterioration of the landscape, and consumption of landfill capacity. Mixing of C\&DW with municipal solid waste is a real issue because of the nonexistence of effective systems and rules for segregation of C\&DW in many countries

Mr. A. R. Makegaonkar, Dr. P. S. Dange, Mr. R. B. Waghmode et. al. 2018 Stated that the main focus of these study is how to reduce the construction waste generated by reusing and recycling the construction and demolition waste our approach is to fulfill the increasing demand of the resources by providing the recycled materials and to minimize the earth pollution.

Piyush P. Mandlik et. al. 2017 Mentioned that Construction waste material management means utilization of the waste generated from Construction activities by using various management techniques. The recycled concrete aggregates can be used alternative to the natural aggregates and manufactured sand can also be used for alternative to natural sand. The strength of concrete mixed designed with recycled aggregate is 10 to 15 per cent less as compared to natural aggregate concrete. 
Minaxi rani et. al. 2016 has concluded that Construction and demolition waste has been defined as ,wastage which are arising from construction, damaged products and material arising in the course of construction work and on site work. The primary method is adopted in waste handling is carried through by interviewing professionals like project managers, architects, civil engineers, contractors and government officials like city engineers, solid waste management officials.

Harish. P. Gayakwad et. al. 2015 has identified that begin with the issue there is no proper estimate regarding the quantity of waste occurs in India . The primary reason is being in disciplinary and less focused in this issue. In this problem there is absence of regulatory framework and strict enforcement. Specific recommendations has made in this paper to overcome the loop holes in the issue. In this paper current global status of construction and demolition waste management is overviewed and also the sustainable waste management hierarchy is studied so to overcome the waste problem.

\section{DATA COLLECTION}

The collection of data deal with feedbacks from different stakeholders (Site Engineers, Contractor and Project Managers) and analysis and discussion of information gathered from the site visit. The details of various stakeholders who were approached during field survey. Further it gives details of responses received for data analysis. This also includes the identification of various causes of waste in construction and their attitudes \& perception towards construction waste management in construction industry. Data analysis of survey responses was carried out and the results are explained in detail

\section{DATA ANALYSIS}

Show the chart not table After the survey and analyzing the data from six different site in interpret the following construction waste which could be affected during the particular working period so, below the different construction waste are follow

\section{Graph - 1 Data collection of steel for six industrial construction site}



Graph - 2 Data collection of bricks for six industrial construction site

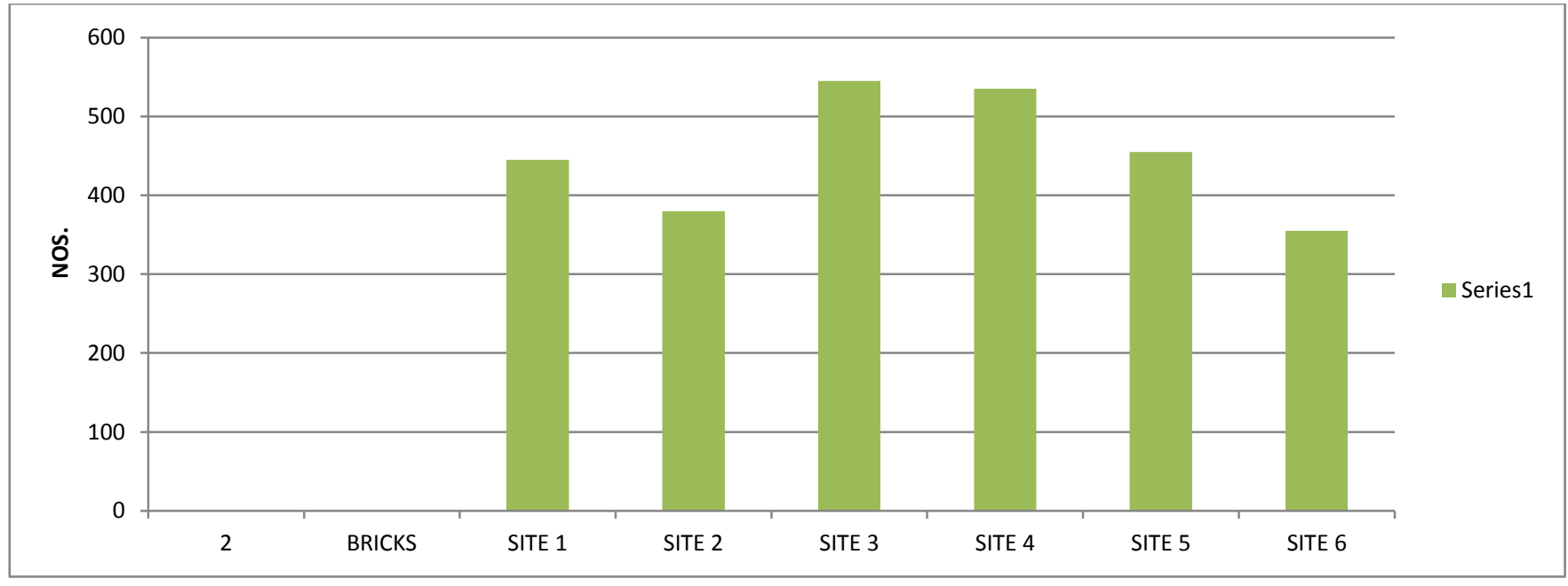


Graph - 3 Data collection of sand for six industrial construction site

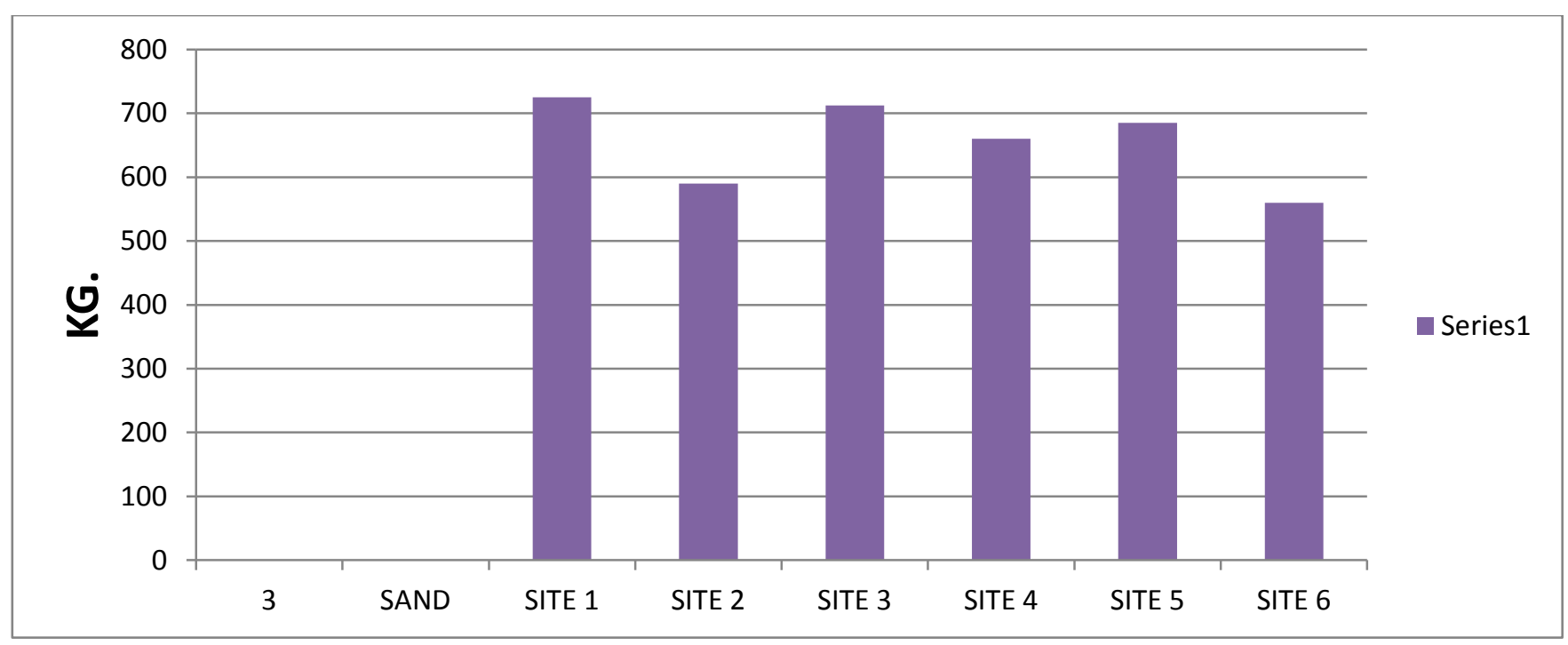

Graph - 4 Data collection of aggregates for six industrial construction site

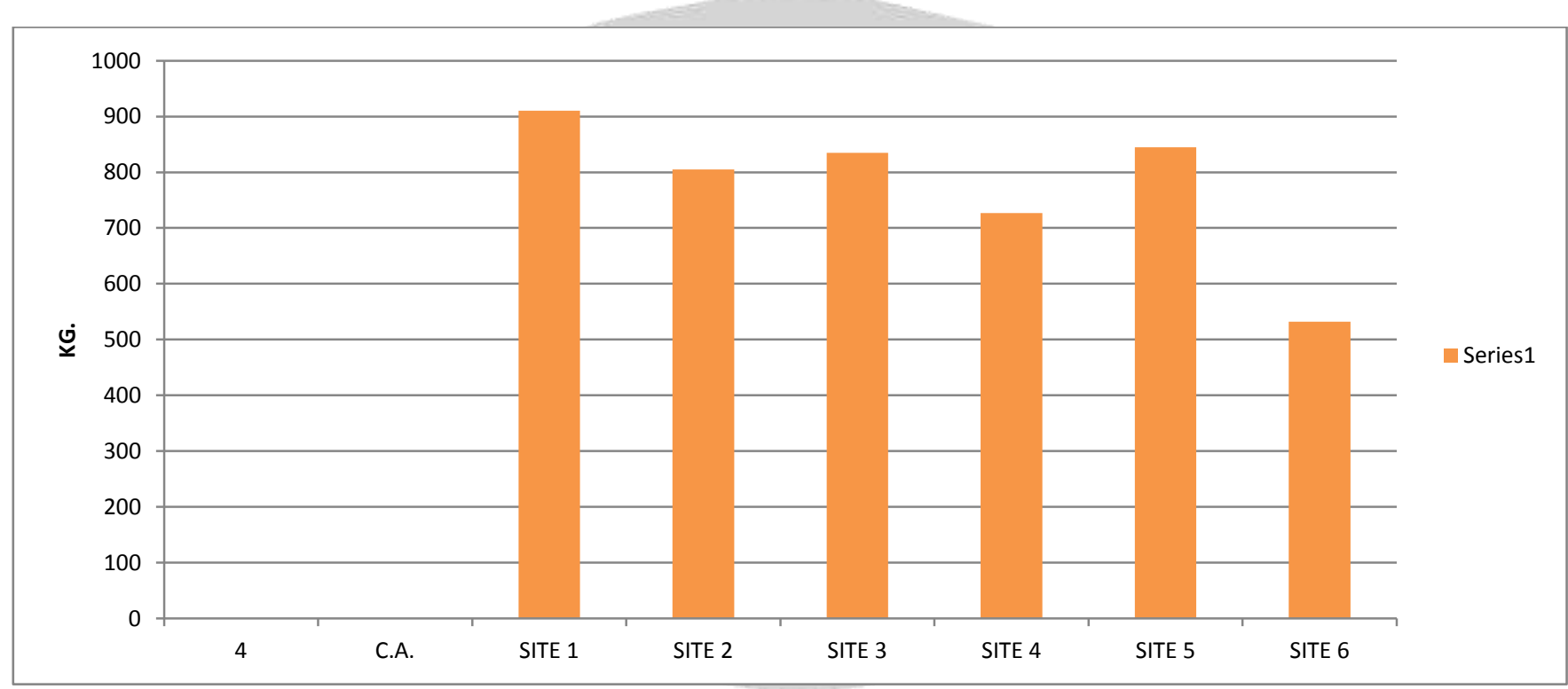

Graph - 5 Data collection of cement for six industrial construction site




Graph - 6 Data collection of concrete for six industrial construction site

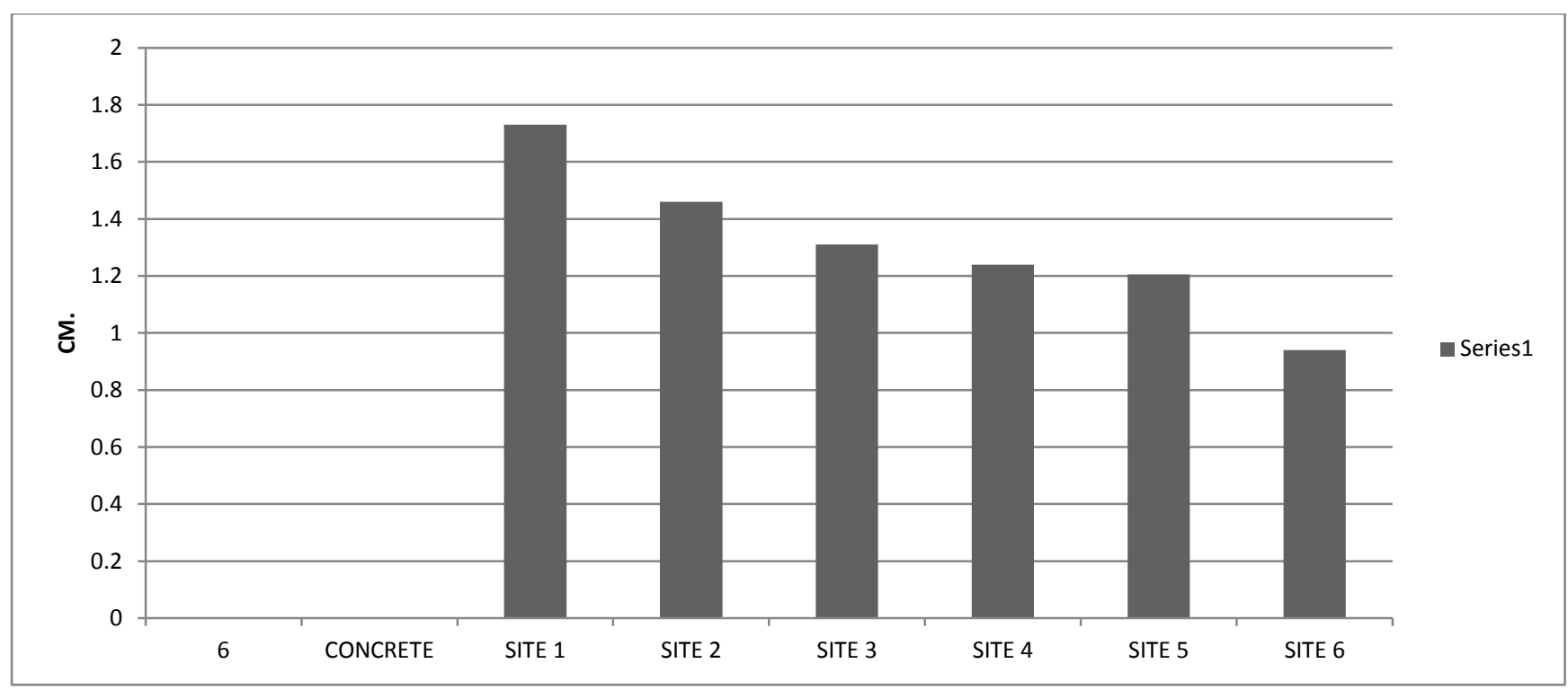

\section{CONCLUSION}

This study has focused to get the probable quantity of material generated at construction project. And after conducting case study on different construction projects, conclusion can be drown that materials like steel, concrete, brick, cement which are always utilized in bulk having the maximum wastage of the site. If appropriate disposal ways would not identified then this material would create issues and harm the environment as well. Looking towards the seriousness from this concern common results of waste generate in construction industry has been identified which must be taken care to improve the value of material.

$>$ In proper storage of material at site location for example sand, aggregates, etc.

$>$ Un skills labours and lack of supervision

$>$ Lack of onsite materials control and waste management planning

$>$ Poor material scheduling.

$>$ Lack of experience Shortage of skilled workers

$>$ Delay in material selection and approval

$>$ Lack of material management system

$>$ Poor communication between project manager and contractor

The average percentages of the private construction site is $1.52 \%$ and government construction is $2.94 \%$

\section{REFERENCES}

[1] Florin-constantin mihai, consruction and demolition waste in romania: the route from illegal to building materials, sustainability 2019,11,3179

[2] Mr. A. r. Makegaonkar , dr. P.s.dange,mr. R.b.waghmode, study of construction and demolition waste for reuse and recycle, international journal of civil engg. And tech.(ijciet), volume 7 ,
[3] Rema. $\mathrm{R}$,nalanth.n, vincent.p, janardhanan k.a., review of the current construction and demolition waste management framework, international journal of civil engg. And tech.(ijciet), volume 9,

[4] Piyush p. Mandlik,ghulam mohammad,shubham morey,sushant malik,mr. Shakil khan , c \& d waste material management in construction industry of nagpur region, international research journal of engg. And thch.(irjet) volumn 04

[5] Minaxi rani, alisha gupta , construction waste management in india, international journal of science technology and management(ijstm), volumn : 05

[6] Avhad varsha,deore nutan,korade dipali,yadav anjali,uday pathak, study the construction and demolition wastes and reuse of it in construction, international journal of engg. Science and computing, volumn : 06

[7] Markandeya raju ponnada, kameswari, construction and demolition waste management - a review , international journal of advanced science and tech, volumn: 84

[8] Harish. P. Gayakwad, neha. B. Sasane , construction and demolition waste management in india, international research journal of engg. And tech.(irjet), volumn : 02

[9] Job thomas, wilson p.m., construction waste management in india , american journal of engg. Research(ajer),volumn: 02

[10] Jingkuang liu and yousong wang "cost analysis of construction and demolition waste management" the open construction and building technology journal, 2013, 7, 251263

[11] Rajendra b. Waghmode, dr. Purushottam s. Dange, "domestic waste water treatment using modified root zone technology". "international journal for scientific research \& development" vol. 5, issue 09, 2017 ,issn (online): 2321-0613

[12] Sawantsurendra b., hedaoomanoj, kumthekarmadhav "impact of the construction waste on the cost of the project" international journal of engineering research volume no.5, issue special $1 \mathrm{pp}: 126-128$ 